\title{
Virtual simulations in the teaching-learning process of physiotherapy: innovative proposal
}

\begin{abstract}
Introduction: The learning process has changed its methodology as well as its tools, due to the students' profile transformation and the advance of technology. The way the students are taught and assessed is still a challenge to the professor. In this context, Influence Diagram (ID) are appropriate to simulate many aspects of the clinical thinking.

Objective: Thus, the main objective of this study is to propose a computerized simulator, structured in ID, a probabilistic network that will be built to develop and evaluate the knowledge of physiotherapeutic assessment.

Method: This is a methodological study. Results: Structured simulators in ID make the abilities and knowledge training safer, in controlled environment and allows to the student a constant assess. Therefore, we proposed the building of a simulator, aiming to train the abilities and competences, in a pleasant and stimulating way to the student.

Final considerations: We hope that this supporting tool to the learning methodology in the physiotherapeutic assessment could be integrated to the curricular unity to train the students, to enlarge their knowledge as well as their capacity to make decisions, and also to develop and boost the students' competences and abilities, minimizing the problems in physiotherapeutic assessment.
\end{abstract}

Keywords: clinical education, evaluation, influence diagram, physical therapy, virtual simulation
Volume 7 Issue 2 - 2020

\author{
Patrícia da Silva Klahr,' Danielle Rachel dos \\ Santos Carvalho, ${ }^{2}$ Luís Henrique Telles da \\ Rosa, ${ }^{3}$ Cecília Dias Flores, ${ }^{4}$ Rodrigo Della \\ Méa Plentz ${ }^{5}$ \\ 'PhD student in Rehabilitation Sciences, Federal University of \\ Health Sciences of Porto Alegre, Brazil \\ ${ }^{2} \mathrm{PhD}$ in Biotechnology, National Simulation Specialist at the \\ School of Health Sciences of Laureate, Brazil \\ ${ }^{3} \mathrm{PhD}$ in Biomedical Gerontology, Professor at the Federal \\ University of Health Sciences of Porto Alegre, Brazil \\ ${ }^{4} \mathrm{PhD}$ in Computing, Professor at the Federal University of \\ Health Sciences of Porto Alegre, Brazil \\ ${ }^{5}$ Doctor of Medicine; Professor at the Federal University of \\ Health Sciences of Porto Alegre, Brazil
}

Correspondence: Patrícia da Silva Klahr, PhD student in Rehabilitation Sciences, Federal University of Health Sciences of Porto Alegre (UFCSPA), Rua Sarmento Leite, 245, Porto Alegre, Rio Grande do Sul, Brazil, Pin code 90050- I70, Tel +55 (5I) 98207-I54I, Email patricia.klah@gmail.com

Received: January 20, 2020 | Published: March 19, 2020
Abbreviations: $\mathrm{BN}$, bayesian networks; $\mathrm{PN}$, probabilistic network; ID, influence diagram; CPMR, cardiopulmonary and metabolic rehabilitation

\section{Introduction}

The learning of the physiotherapeutic assessment and clinic thinking is one of the main points of the formation of the physiotherapy students. In clinic physiotherapy practice, we should be aware of the previous probabilities established in the decision-making, not only to the assessment or physiotherapeutic diagnoses, but also to the establishment of prognostic and decisions of treatment. This judicial use of conditional probabilities conditionals, adapted to each evidence, acquired in clinic investigation, is formally described in Bayes Theorem. ${ }^{1}$

We should stimulate our students to make decisions, based on scientific evidences, still thinking on learning as a constant evolution, considering the students' profile of the XXI century, the technological tools, which are available, and the daily decision-making. It is also necessary to make the students question about the possibility of the use of the supporting system to the decision-making, in order to assist the assessment of physiotherapeutic learning and decision-making during the evaluation of a clinic case. ${ }^{2}$

Considering the area of the supporting decision-making study, we highlight that there are some systems, based on probabilistic network $(\mathrm{PN})$, that are network that represents uncertain knowledge, ${ }^{3}$ useful and easy to characterize tool that has given support to the decision making as well as to the clinic thinking and contributed to the learning health process. ${ }^{4-6}$
As a computerized tool, the simulators promotes the training of abilities and development of competences, in a safety way, in a controlled environment that allows a constant evaluation of the student during the whole process of the simulation. ${ }^{7}$ The building of a structured simulator, based on the Bayesian Networks (BN), that have the knowledge of the physiotherapeutic assessment, designed by a professor of a curricular unity, in order to stimulate practical situations of the physiotherapeutic assessment, is a proposal of a pedagogical strategy, aiming to improve the learning process.

Another variation of BN, called "Influence Diagram" (ID), can perceive the behavior and the pattern of the decision-making during the study, customizing pedagogical strategies to each profile of the student. Besides, among the systems that can use the probabilistic thinking, there are the ones that give support to the decision-making, which are used to give support to the analyses of the variables, the probabilities and decision-making. ${ }^{3-5,8}$ The simplest system decision-making uses just known facts (true and false propositions), in order to make inferences, based on mathematical theories and new conceptions, to enable them to make decisions. ${ }^{9}$ However, the uncertainty is of the most important traits of the universe, that can be minimized, but never completely eliminated, the problem to get real information about the environment justifies the use of the techniques or probabilistic thinking. ${ }^{10,11}$

These methods can be used in a proper way in environments, in which information are partial or incomplete, such as in heath area, because it is very difficult to the professional to access all the necessary information to get to a conclusion in a precise and rapid way. ${ }^{5,9,11}$ In other circumstances, it is not known whether the information is true or 
false, due to impossibility or theoretical unfamiliarity. Thus, working with lack of information means to deal with uncertainty ${ }^{10}$ and train to make decisions, based on the available information.

Aiming to surpass this constrain, students need to be able and adapted, to act, considering uncertainty. ${ }^{9,10} \mathrm{So}$, PN gives support to the development of the thinking diagnoses and the modeling diagnosis hypothesis, even though when there is uncertainty. Apart from that, it accesses the selected evidences, the relations between evidences and the probability of the evaluation to be corrected, as well as it demonstrates all the probabilities of the interrelations among all the different interference and outcome variables. ${ }^{3}$ In other words, a PN, modulated by the professor of the curricular unity, will deal with the relevant outcomes related to the universe of the problem, in a similar way of the modeler's thinking and emulating his/her reasoning, in the same that It is used in the discipline.

PN are highly versatile models, with increasing amplitude in different areas. The models are able to structure and measure the integration among variables, making it possible to accomplish different types of analyses, from diagnosis to previsions, ${ }^{1}$ as well as it allows the building models of decision-making.

The use of these networks shows the following characteristics: a) it allows to represent and manipulates the uncertainty, based on grounded mathematical principles; $b$ ) it modulates the knowledge of the professor who has the domain of the area in an intuitive way; c) this is the unique formalism that allows making any possible types of probabilistic inference, that is, causative, diagnostic, inter-causal or mixed. ${ }^{3,4,12,13}$

The ID, an example of BN, is a technique of artificial intelligence that gives support to the decision-making. ${ }^{9}$ It, through the combination of probabilities, provides possibilities to decision-making and its respective chances of success. It is represented by graphs, where there are nodes of uncertainty, decision and utility. Through the combination of variables, in each node, we get all the suggestions, whose objective is to give support to the process of decision-making., ${ }^{5,14}$

The ID can crystalize an expert's knowledge in an computerized tool, $, 3,4,6,8$ that will help the student, who is less experienced, to make decisions, based on the analyzes of a certain set of known evidences. ${ }^{15}$

A simulator can make probabilistic inferences about the students' actions, in order to build a student model, based on their level of confidence and in their decision-making, used the ID as a motor of inference, presented to the student.

The simulator give support to decision-making training related to the physiotherapeutic assessment, and it will help to train the choice, considering which questions are relevant and adequate for the specific clinic case. Besides, it will help the students to verify the level of the confidence, taking into consideration the execution of the questions, helping them to determine their level of confidence in the decisionmaking process.

The appropriate learning, supported by simulators, gives the student the opportunity to test different ways to solve the same problem. ${ }^{16}$ The students can also explore, in a pleasant and playful way, the complex relations among the variables that are related, while they search for a solution to a problem that can be closer to the ideal proposed result. It also allows an educational reinforcement, necessary to the consolidation of the acquired knowledge, when simulating a realistic scenario in the application of this knowledge. ${ }^{17}$

Simulation is a teaching tool that already has differential between the traditional teaching method, and a simulated situation. As systematic reviews have demonstrated the effectiveness of simulation in miscellaneous expertise and educational fields. ${ }^{15-17}$ Various types of simulations are already carried out in health care to train the skills of professionals in the field of surgery that is very common. However, beyond technical abilities it is necessary to invest in simulation that helps making the professional decision, looking beyond the skills some specific skills of health professionals. Besides, simulation is great for providing an immediate and particular feedback to each student. ${ }^{18-20}$

Recent research has shown the viability in the use of ID in processes where variables are uncertain and decisions need to be taken starting from the probabilistic dependency in a flow of information as, for instance, in the medical field and risk evaluation. ${ }^{15,16}$

The ID is presented in this paper in the selection of the best Cardiopulmonary and Metabolic Rehabilitation (CPMR) option for cardiac patients in a safe and effective way. Many studies on the enormity of the prevalence of heart disease suggested some treatment possibilities in order to minimize the negative effects of these disorders in patient's quality of life. ${ }^{21-23}$ There emerged the possibility of a nonpharmacological treatment, the Cardiopulmonary and Metabolic Rehabilitation (CPMR). ${ }^{24,25}$

CPMR is the sum of the activities needed to ensure patients with heart disease better physical, mental and social conditions. ${ }^{24-26}$ Patients who adhere to CPMR programs have improved quality of life, hemodynamic stabilization, metabolic changes, and improved vascular and psychological states, which are associated with better control of risk factors and improvement in lifestyle. ${ }^{25,26}$ Studies have already demonstrated the cost-effectiveness of CPMR, which became necessary for the rehabilitation of patients affected by these diseases, ${ }^{24-26}$ if well assessed the patient. However, there are several uncertainties surrounding the professionals who work in CPMR.

Although the beliefs are strengthened and the uncertainties are reduced over the years of experience and professional practice, there will always be a degree of uncertainty in each decision. A classic example observed in clinical practice is the prevalent use of the treadmill, with the use of the stationary bicycle restricted to patients who have a physical or mental limitation that prevents treadmill training.

However, there are still uncertainties about whether the equipment chosen by the professional is suitable for the patient's specific clinical picture..$^{27,28}$

Thus, based on the technological advances, the possibility of building decision support systems and the high prevalence of heart disease, and especially the need to teach future physical therapy to adequately assess a patient and make the right decision facing the clinical case, this study aims to describe the importance and propose of new tool of education in health science.

\section{Materials and methods}

This is a methodological study approved by the Research Committee (ComPesq) of the Federal University of Health Sciences of Porto Alegre (UFCSPA) under number 011/2013, in which the Helsinque Declaration was respected.

\section{Participants}

The data used in this study were obtained from the medical records of a cohort of cardiac patients in phase II at CPMR assigned by a referral center for cardiopulmonary and metabolic rehabilitation in the state of Rio Grande do Sul, Brazil. 


\section{Influence diagram development and validation}

The methodology used to generate the ID, characterization and validation is described in details in the paper Klahr et al. ${ }^{28}$ where the group carried out the first publication describing the data used for the built of the ID. Based on this the ID development, think of transform in a simulator of clinical cases, where the ID would be the inference in the evaluation simulation environment engine and patient decisionmaking.

The ID would provide the analysis of the decisions taken by the student. Once held one clinical case simulation in virtual learning environment, students could be asked about what questions, or questions should be done for the patient, and based on the logic of the sequence and execution of response, analyze what is the real possibility of diagnosis. And in the specific case of front decision rehabilitation of this patient. The proposal is a virtual simulation, and an education based on clinical cases expressed in virtual environment.

\section{Results}

The quantitative data used for modeling the shape ID were obtained from a cohort of patients who attended a referral center from April 2012 to April 2013. From the variables defined according to the guidelines and consensus and the data obtained in the cohort of patients we obtained the ID below (Figure 1). ${ }^{28}$

The ID can represent the mutual and hierarchical relations among many variables using probabilistic rules and, therefore, in many cases their application is more suitable for prognosis and diagnosis (Figure 2). ${ }^{28}$ We perform ID validation, which allows us to create multiple clinical cases to convert into virtual simulations for the student to make the decision of what to do during a patient's assessment. From these data, we can determine the key issues assess for the decision on the patient's rehabilitation and simulate the clinical cases for development the student based on real situations of CPMR.

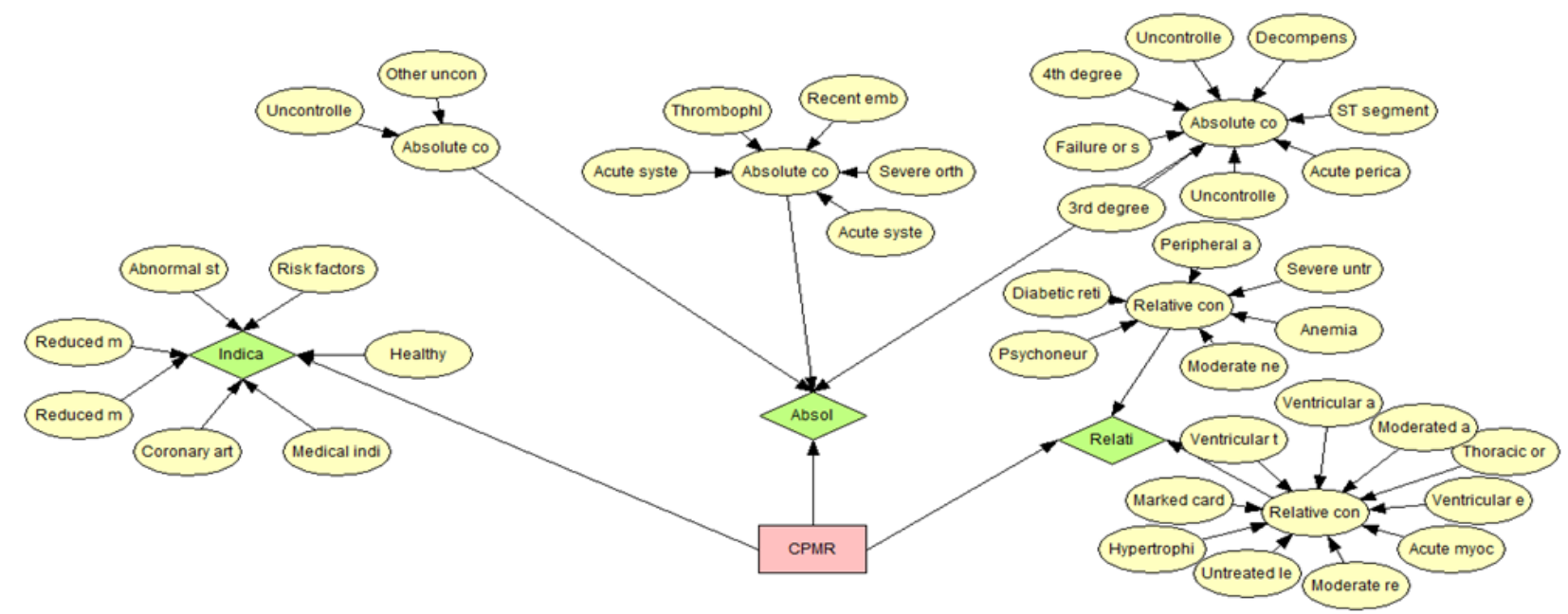

Figure I Influence diagram structured to assist in decision making to perform cardiopulmonary and metabolic rehabilitation.

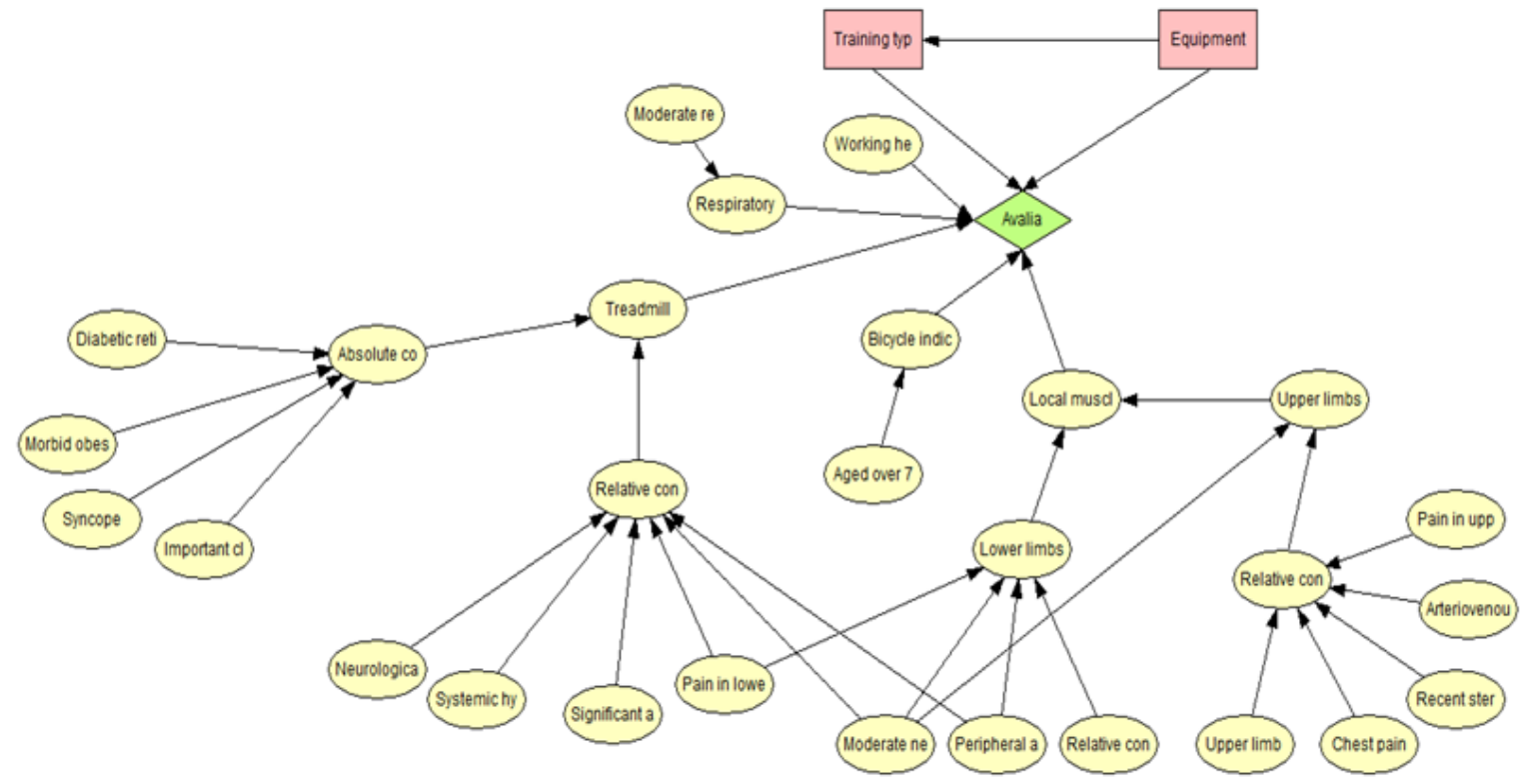

Figure 2 ID structured to assist in decision making regarding type of equipment and training. 
We present 3 randomly selected cases from the database to display the variables, the decision of the expert and the decision of the ID:

a. Patient W.L.B., male, 86 years old, $83 \mathrm{Kg}, 1.60 \mathrm{~m}$ height, BMI (body mass index) $=32 \mathrm{~kg} / \mathrm{m}^{2}$, resting HR (heart rate) $41 \mathrm{bpm}$. Main complaint is fatigue that comes to feel dizzy, but also refers severe pain in lower and upper limbs. Has positive family history of CAD, is sedentary, stress test is abnormal, predicted maximum inspiratory pressure at $115 \%$. The decision of the expert is to send this patient for the following conduct:. Stretches (flexibility), bike to a HR of 96bpm working with the Borg scale below 3. There is no need for FES (functional electrical stimulation) and IMT (inspiratory muscle training) at the time and would not tolerate the treadmill. The decision proposed by the ID was: In failure to perform treadmill, perform bike; indicates the FES, with lower value indicates the RML (located muscle strengthening), does not indicate the IMT and indicates the flexibility. ID also makes reference to the preferable aerobic intensity.

b. Patient L.A.P., male, 48 years old, $76.5 \mathrm{~kg}, 1.68 \mathrm{~m}$ height, BMI (body mass index $)=27 \mathrm{~kg} / \mathrm{m}^{2}$, resting HR $67 \mathrm{bpm}$. Main complaint is chest pain. Patient referred not having other symptoms or risk factors such as dyslipidemia, hypertension and family history. Was treated with beta-blockers, anticoagulants and statins; lacked effort and the predicted maximum inspiratory pressure is $105 \%$. The decision of the expert is to send this patient for the following conduct: Stretches (Flexibility); if the patient was not on betablockers, he could be working at a HR of $130 \mathrm{bpm}$, with a range of less than 4borg. There is no need for FES and the IMT. The decision proposed by the ID was: Biggest indication to perform the wake of that bike, indicates the FES, with lower value indicates the RML, and does not indicate the IMT; indicates flexibility. The most indicated type of training is aerobic rather than anaerobic. c. Patient A. D. S., female, 58 years old, $142 \mathrm{Kg}, 1.60 \mathrm{~m}$ height, $\mathrm{BMI}=55 \mathrm{~kg} / \mathrm{m}^{2}$, resting HR $136 \mathrm{bpm}$. AP (arterial pressure) 190/140. Main complaint is fatigue associated with shortness of breath at rest, chest pain, which in some cases reaches fainting and dizziness. Among the risk factors are dyslipidemia, hypertension, decompensated DM, smoking, family history of CAD. Patient states that she has prescriptions but forgets to take the medication. Referred pain in MIE; when the expert did a physical examination he noticed swelling, heat, redness and increased local temperature. The decision of the expert is to send this patient to consult with the specialist because he believes that under such conditions the patient is not able to perform CPMR. The decision proposed by ID contraindicated CPMR.

The predictions obtained with this method can inform the student and the teacher whether a given treatment is being effective or whether a given condition is under control. As the student answers the simulator's questions, the simulator itself conducts feedbacks and supports decision making in order to support the student in decision making. At the same time, the teacher can have access to student choice records to perform interventions and support the teachinglearning process.

\section{Future proposition}

Construct an attractive layout that envisions a collaborative learning environment, where the inference engine is the ID already built and validated. The proposal is to elaborate questions where the student can respond according to his level of confidence and knowledge (Figures 3\&4).
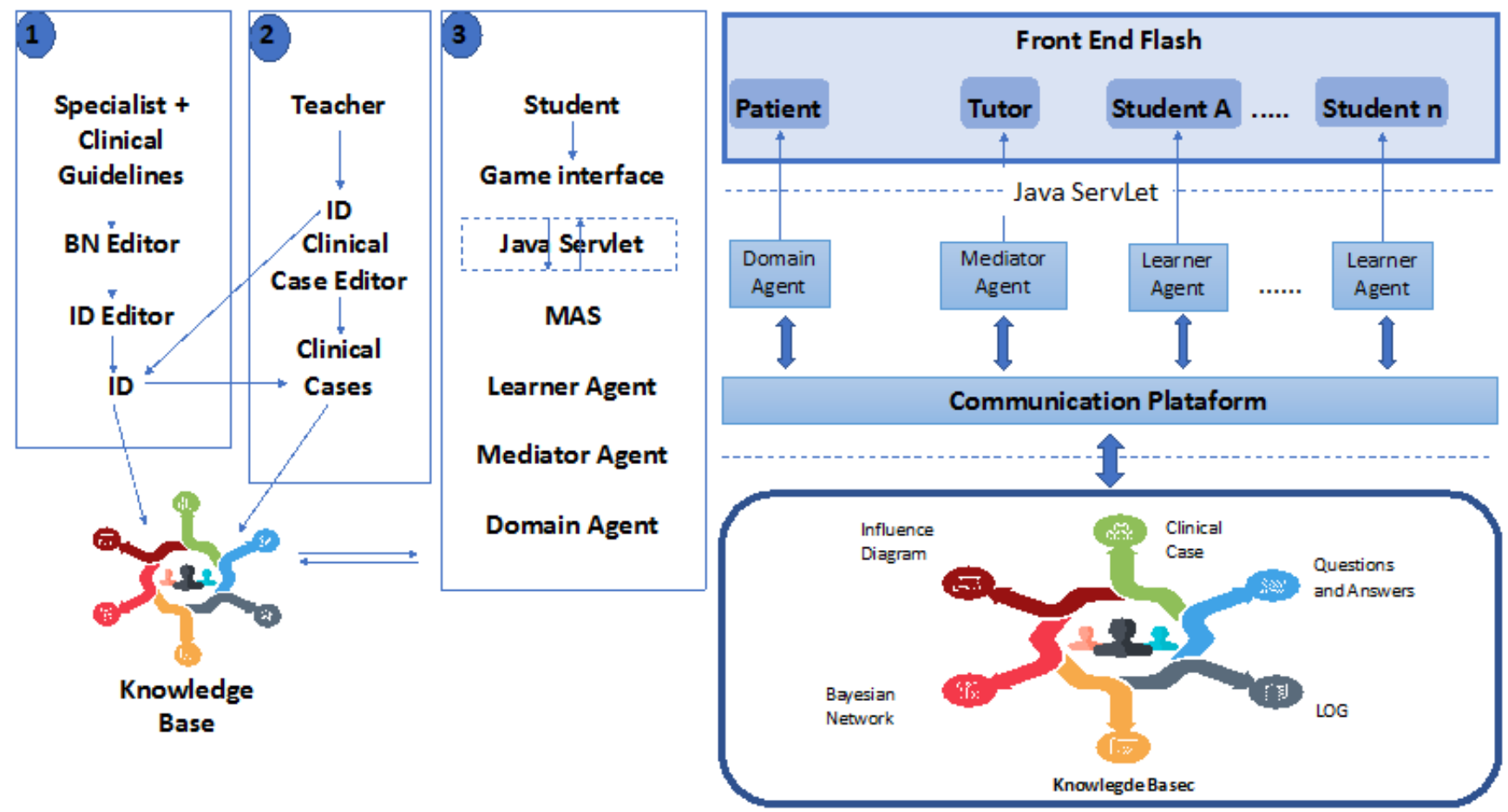

Figure 3 Illustration of the learning environment layout. 


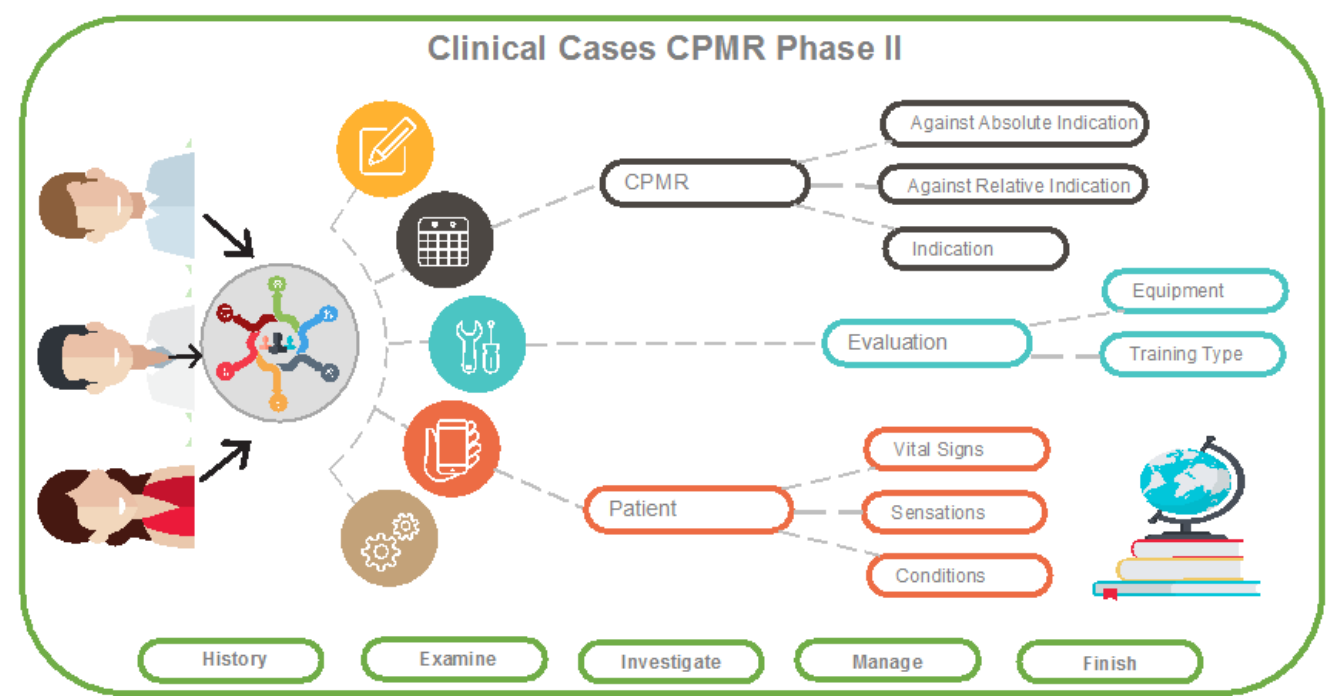

Figure 4 Example illustration of the clinical cases.

\section{Discussion}

In the present study we attempted to integrate the information obtained in consensus guidelines and current scientific literature with data obtained in a cohort of patients with the interpretation by experts in order to propose a model to implement a ID. This method explains all the relations between the predictors and outcomes in a graphical model that incorporates uncertainty through the conditional probability associated with each node. .,2,28,29 $^{2}$

We understand that the BN and ID can be used in decision support systems in the CPMR. The influence diagram, which is a BN modified to decision making, can provide the necessary tools to generate ideas on the decisions to be made. ${ }^{1,16,28}$ This ID can be used as build inference motor of a Simulator of Clinical Cases in Health, in order to obtain a tool to be used in cardiac rehabilitation classes and make it available to academic students of physical therapy to assist in the learning of phase II CPMR (Table 1). ${ }^{30}$

Several studies have evaluated the effectiveness of the use of simulation for skills training and education in health, suggest the effectiveness of this tool ahead to other teaching tools or associated with these. ${ }^{31-33}$ As McGaghie et al..$^{32}$ simulation-based education "is not easy or intuitive; clinical experience alone is not a proxy for simulation instructor effectiveness". As simulation is increasingly used in health professional education, showing superior to tradicional clinical medical education in achieving specific clinical skill acquisition goals ${ }^{33}$

Table I Patient data, clinical history and decision of the expert and the decision of the ID

\begin{tabular}{|c|c|c|c|c|c|}
\hline Patient & Variables & Outcomes & & Expert & ID \\
\hline W.L.B. & Gender & male & & & \\
\hline & Body Mass Index (BMI) & $32 \mathrm{~kg} / \mathrm{m}^{2}$ & $\begin{array}{l}\text { Main complaint is fatigue } \\
\text { that comes to feel dizzy, } \\
\text { but also refers severe pain } \\
\text { in lower and upper limbs. } \\
\text { Has positive family history } \\
\text { of CAD, is sedentary, stress } \\
\text { test is abnormal, predicted } \\
\text { maximum inspiratory } \\
\text { pressure at II } 5 \% \text {. }\end{array}$ & $\begin{array}{l}\text { The decision of the } \\
\text { expert is to send this } \\
\text { patient for the following } \\
\text { conduct:. Stretches } \\
\text { (flexibility), bike to a HR } \\
\text { of } 96 \mathrm{bpm} \text { working with } \\
\text { the Borg scale below } 3 \text {. } \\
\text { There is no need for } \\
\text { FES (functional electrical } \\
\text { stimulation) and IMT } \\
\text { (inspiratory muscle } \\
\text { training) at the time and } \\
\text { would not tolerate the } \\
\text { treadmill. }\end{array}$ & $\begin{array}{l}\text { The decision proposed by } \\
\text { the ID was: In failure to } \\
\text { perform treadmill, perform } \\
\text { bike; indicates the FES, } \\
\text { with lower value indicates } \\
\text { the RML (located muscle } \\
\text { strengthening), does not } \\
\text { indicate the IMT and } \\
\text { indicates the flexibility. ID } \\
\text { also makes reference to the } \\
\text { preferable aerobic intensity. }\end{array}$ \\
\hline
\end{tabular}

Resting HR (heart rate) $4 \mathrm{lbpm}$ 


\begin{tabular}{|c|c|c|c|c|c|}
\hline Patient & Variables & Outcomes & & Expert & ID \\
\hline \multirow{5}{*}{ L.A.P. } & Gender & male & \multirow{4}{*}{$\begin{array}{l}\text { Main complaint is chest pain. } \\
\text { Patient referred not having } \\
\text { other symptoms or risk } \\
\text { factors such as dyslipidemia, } \\
\text { hypertension and family } \\
\text { history. Was treated with } \\
\text { beta-blockers, anticoagulants } \\
\text { and statins; lacked effort } \\
\text { and the predicted maximum } \\
\text { inspiratory pressure is } 105 \% \text {. }\end{array}$} & \multirow{4}{*}{$\begin{array}{l}\text { The decision of the } \\
\text { expert is to send this } \\
\text { patient for the following } \\
\text { conduct: Stretches } \\
\text { (Flexibility); if the patient } \\
\text { was not on betablockers, } \\
\text { he could be working at } \\
\text { a HR of I } 30 \text { bpm, with a } \\
\text { range of less than } 4 \text { borg } \\
\text { There is no need for FES } \\
\text { and the IMT. }\end{array}$} & \multirow{4}{*}{$\begin{array}{l}\text { The decision proposed by } \\
\text { the ID was: Biggest indication } \\
\text { to perform the wake of that } \\
\text { bike, indicates the FES, with } \\
\text { lower value indicates the } \\
\text { RML, and does not indicate } \\
\text { the IMT; indicates flexibility. } \\
\text { The most indicated type of } \\
\text { training is aerobic rather than } \\
\text { anaerobic. }\end{array}$} \\
\hline & Age (years old) & 48 & & & \\
\hline & Weight & $76.5 \mathrm{~kg}$ & & & \\
\hline & Body Mass Index (BMI) & $27 \mathrm{~kg} / \mathrm{m}^{2}$ & & & \\
\hline & Resting HR (heart rate) & 67 bpm & & & \multirow{10}{*}{$\begin{array}{l}\text { The decision proposed by ID } \\
\text { contraindicated CPMR. }\end{array}$} \\
\hline \multirow[t]{9}{*}{ A.D.S. } & Gender & female & \multirow{9}{*}{$\begin{array}{l}\text { Main complaint is fatigue } \\
\text { associated with shortness } \\
\text { of breath at rest, chest } \\
\text { pain, which in some cases } \\
\text { reaches fainting and dizziness. } \\
\text { Among the risk factors are } \\
\text { dyslipidemia, hypertension, } \\
\text { decompensated DM, } \\
\text { smoking, family history of } \\
\text { CAD. Patient states that she } \\
\text { has prescriptions but forgets } \\
\text { to take the medication. } \\
\text { Referred pain in MIE; when } \\
\text { the expert did a physical } \\
\text { examination he noticed } \\
\text { swelling, heat, redness and } \\
\text { increased local temperature. }\end{array}$} & \multirow{9}{*}{$\begin{array}{l}\text { The decision of the } \\
\text { expert is to send this } \\
\text { patient to consult with } \\
\text { the specialist because he } \\
\text { believes that under such } \\
\text { conditions the patient } \\
\text { is not able to perform } \\
\text { CPMR. }\end{array}$} & \\
\hline & & & & & \\
\hline & Age (years old) & 58 & & & \\
\hline & Weight & $142 \mathrm{Kg}$ & & & \\
\hline & Height & $1.60 \mathrm{~m}$ & & & \\
\hline & Body Mass Index (BMI) & $55 \mathrm{Kg} / \mathrm{m}^{2}$ & & & \\
\hline & Resting HR (heart rate) & 136 bpm & & & \\
\hline & & & & & \\
\hline & Arterial Pressure & $190 / 140$ & & & \\
\hline
\end{tabular}

3 randomly selected cases from the database

\section{Simulation benefits}

Several studies have presented the benefits and effectiveness of simulation, and even systematic reviews have concluded that associating simulation to teaching brings benefits and enhances learning, since simulation allows the student to learn even with his error and practice relentlessly If necessary the same technique, generating skill and safety for the real patient care. ${ }^{34-36}$

The past decades have seen rapidly growing interest in using simulation for purposes of improving patient safety and patient care through a variety of applications. ${ }^{37}$ Hendrik et al., ${ }^{36}$ stated that the conflict between necessary education and the lack of practical training can be balanced by simulation of various aspects of clinical practice. Simulations of both high fidelity and skill training, virtual simulations or instructional desing, support decision making and enhance learning, patient safety, professional qualification, professional interrelationship and interest by studying outside regular classroom hours, enhances self-study. ${ }^{36-41}$

The simulator proposed in this paper helps both to develop and evaluate the knowledge of physiotherapeutic assessment, since the ID validation, allows us to create multiple clinical cases. In this case, we can highlight two important elements that improve student performance: feedback and the opportunity to repeat training. According to Huang et al. ${ }^{42}$ virtual patient programs contains desirable elements of learner-centered instruction, individualized feedback and performance tracking. In addition, several studies have demonstrated that virtual simulation is well received and may improve cognitive and behavioral skills better than traditional methods do.

The benefits of virtual simulation are the possibility to train in an educationally-orientated environment free of the time and cost pressures of learning. The trainee can also be mentored through the case and an objective assessment of performance can also be provided, facilitating the opportunity to provide formative and summative feedback. ${ }^{42-44}$ Additional benefits are that virtual learning environments can take many forms, depending on training requirements. Characteristics represented by the virtual patient/cases can easily be modified. For instance, gender, age, ethnicity, symptoms and more can be altered merely by swapping virtual cases. ${ }^{45}$

\section{Strengths and limitations of the study}

Despite the complexity of the interactions, the model for the implementation of DI seems to be able to predict the scenarios in which the new variables can be incorporated or analyzed and contributes in the health customization process, provides a second opinion for the health student helping the diagnostic, therapeutic process and decision making of the physiotherapist. It can be used as a great tool to support the teaching and learning process. 


\section{Acknowledgements}

None.

\section{Conflicts of interest}

The authors declare there are no conflicts of interest.

\section{Funding}

None.

\section{References}

1. Verduijn M, Peek N, Rosseel PMJ, et al. Prognostic bayesian networks i: rationale, learning procedure, and clinical use. $J$ Biomed Inform. 2017;40(6):609-618.

2. Roshanov PS, Fernandes N, Wilczynski JM, et al. Features of effective computerised clinical decision support systems: meta-regression of 162 randomised trials. $B M J$. 2013;346:f657.

3. Flores CD, Höher CL, Ladeira M, et al. An experience of using probabilistic networks in medical diagnosis. Argentine Symposium on Artificial Intelligenc. 2000

4. Lucas PJF, Gaag LCVD, Abu-Hanna A. Bayesian networks in biomedicine and health-care. Artif Intell Med. 2004;30(3):201-214.

5. Marques RL, Dutra I. Bayesian networks: what they are, what are algorithms and application examples. 2003. 22 p.

6. Saheki AH. Construction of a Bayesian network applied to the diagnosis of heart disease. Engineering master's dissertation from the Polytechnic School of UPS. Department of Mechatronics Engineering and Mechanical Systems. São Paulo. 2005. 84 p.

7. Scalese RJ, Obeso VT, Issenberg SB. Simulation technology for skills training and competency assessment in medical education. Journal of General Internal Medicine. 2008;23:46-49.

8. Goud R, Jaspers, MWM, Hasman A, et al. Subjective usability of the CARDSS guideline-based decision support system. Studies in Health Technology \& Informatics - IOS Press. 2008. p. 193-198.

9. Martani AHD, Forster CHQ. Induction of the structure of Bayesian networks. Proceedings of the 15th of ITA's Scientific Initiation and Postgraduate Meeting. 2009.

10. Noguerol AR. Correction of alarms and diagnostics in the management of computer-supervised systems. 2002. 147p. Conclusion Work (Master in Informatics). Graduate Program in Computing, Federal University of Rio Grande do Sul-UFRGS. 2002.

11. Rodrigues FH. Extraction of Bayesian models from ontologies built for medical diagnosis. Thesis presented at Feevale University to obtain a degree. 2012.

12. Pearl J. Probabilistic Reasoning in Intelligent Systems: Networks of Plausible Inference. 2th ed. Morgan Kaufmann. 1988.

13. Maheronnaghsh R, Nezareh S, Sayyah MK, et al. Developing SNOMEDCT for decision Making and Data Gathering: A Software Prototype for Low Back Pain. Acta Medica Iranica. 2013;51(8):548-553.

14. Kabachinski J. A look at clinical decision Support Systems. Biomedical Instrumentation \& Tecnology. Columns and Departments. 2013.

15. Dereck L Hunt, R Brian Haynes, Steven E Hanna, et al. Effects of Computer-Based Clinical Decision Support Systems on Physician Performance and Patient Outcomes: A systematic review. JAMA. 1998;280:15

16. McKinney J. Simulation-based Training for Cardiac Auscultation Skills: Systematic Review and Meta-Analysis. 2012.
17. McGaghie WC, Issenberg SB, Cohen ER, et al. Does simulation-based medical education with deliberate practice yield better results than traditional clinical education? A meta-analytic comparative review of the evidence. Acad Med. 2011;86(6):706-711.

18. Cook DA, Hatala R, Brydges R, et al. Technology-enhanced simulation for health professions education: a systematic review and meta-analysis. JAMA. 2011;306 (9):978-988.

19. Fletcher GF, Ades PA, Kligfield P. Exercise Standards dor Testing and Training: A scientific Statement from the American Heart Association. Circulation Journal of the Americam Heart Association. 2013;872-934.

20. Taylor RS, Brown A, Ebrahin S, et al. Exercise-based cardiac rehabilitation in patients with coronary heart disease: systematic review and meta-analysisof randomized controlled trials. The American journal of medicine. 2004;116(1):682-692.

21. Cortes-Bergoderi M, Lopez-Jimenez F, Herdy AH, et al. Availability and characteristics of cardiovascular rehabilitation programs in South America J Cardiopulm Rehabil Prev. 2013;33(1):33-41.

22. Carvalho T, Cortez AA, Ferraz A, et al. Cardiopulmonary and metabolic rehabilitation guidelines: practical aspects and responsibilities. Arq Bras Cardiol. 2006;86(1):74-82.

23. Perk J, Backer GD, Gohlke H, et al. European guidelines on cardiovascular disease prevention in clinical practice (version 2012). European Heart Journal. 2012;33(1):1635-1701.

24. Moreira PBB. Cost-effectiveness of cardiovascular rehabilitation programs. Journal of the Department of Ergometry and Cardiac Rehabilitation. 2004;27:14-16.

25. Muela HCS, Bassan R, Serra SM. Evaluation of the Functional Benefits of a Cardiac Rehabilitation Program. Rev Bras Cardiol. 2011;24(4):241250 .

26. Wong WP, Feng J, Pwee KH, et al. A systematic review of economic evaluations of cardiac rehabilitation. BMC Health Services Research. $2012 ; 12: 243$.

27. Ghorayeb N, Costa RVC, Castro I, et al. Guideline in Sport and Exercise Cardiology from the Brazilian Society of Cardiology and the Brazilian Society of Sports Medicine. Arq Bras Cardiol. 2013,100(1Supl.2):1-41.

28. Klahr PS, Corrêa CC, Cabral RC, et al. Influence Diagram As a Support Tool for Clinical Decisions In Cardiopulmonary And Metabolic Rehabilitation. Studies in health technology and informatics. 2014;216:290-294.

29. Berchialla P, Foltran F, Bigi R, et al. Integrating stress-related ventricular funtional and angiographic data in preventive cardiology: a unified approach implementing a Bayesian Network. Journal of Evaluation in Clinical Practice. 2012;18:637-643.

30. Vicari RM, Flores CD, Silvestre AM, et al. A multi-agent inteligente environment for medical knowlwdge. Artificial Intelligence in Medicine. $2003 ; 27: 335-366$.

31. Nestel D, Bearman M, Brooks P, et al. A national training program for simulation educators and technicians: evaluation stratgey and outcomes. BMC Medical Education. 2016;16:25.

32. McGaghie WC, Issenberg SB, Petrusa ER, et al. A critical review of simulation-based medical education research: 2003-2009. Med Educ. 2010;44(1):50-63.

33. Issenberg SB, Mcgaghie WC, Petrusa ER, et al. Features and uses of high-fidelity medical simulations that lead to effective learning: a BEME systematic review. Medical Teather. 2009;10-28.

34. Ziv A, Ben-David S, Ziv M. Simulation Based Medical Education: an opportunity to learn from errors. Medical Teather. 2009;193-199. 
35. Gaba DM. The future vision of simulation in health care. Qual Saf Health Care. 2004;13(Suppl 1):i2-i10.

36. Hendrik F, Weissenstein A, Ligges S, et al. Combining simulated patients and simulators: pilot study of hybrid simulation in teaching cardiac auscultation. Advances in Physiology Education. 2014;38:343-347.

37. Khan K, Pattison T, Sherwood M. Simulation in medical education Medical Teather. 2010. p.1-3.

38. Cook DA, Hamstra SJ, Brydges R, et al. Comparative effectiveness of instructional design features in simulation-based education: Systematic review and meta-analysis. Medical Teather. 2012.

39. Bezemer J. Visual research in clinical education. Medical Education. 2017;51:105-113.

40. Barbosa J, Silva A, Ferreira MA, et al. The impact of students and curriculum on self-study during clinical training in medical school: a multilevel approach. Medical Education. 2017;17:9.
41. Sorensen JL, Ostergaard D, LeBlanc V, et al. Design of simulation-based medical education and advantages and disadvantages of in situ simulation versus off-site simulation. BMC Medical Education. 2017;17:20.

42. Huang G, Reynolds R, Candler C. Virtual Patient Simulation at U.S. and Canadian Medical Schools. Academic Medicine. 2007;82:5.

43. Krummel TM. Surgical simulation and virtual reality: the coming revolution. Annals of Surgery. 1998;228:635-637.

44. Aggarwal R, Moorthy K, Darzi A. Laparoscopic skills training and assessment. British Journal of Surgery. 2004;91:1549-1558.

45. Hubal RC, Kizakevich PN, Guinn CI, et al. The virtual standardized patient. Simulated patient-practitioner dialog for patient interview training. Studies in Health Technology and Informatics. 2000;70:133138. 